\title{
A INDÚSTRIA NO PAÍs ESTÁ PREPARADA PARA A GRANDE
}

TRANSFORMAÇÃO
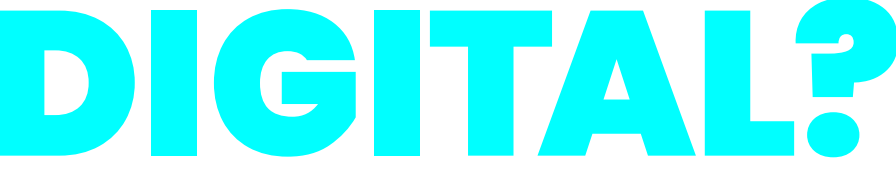

Francisco Gaetani e Virgilio Augusto Fernandes Almeida

O tempo se acelerou. Primeiro foi a globalização. Seguiu-se a hiperconectividade. Em algum momento o analógico deu a vez ao digital. Veio a crise financeira de 2007/2008. A emergência climática começou a desenhar-se com nitidez já na Rio+20. As redes sociais explodiram. As múltiplas inovações trazidas pela transformação digital irromperam na vida cotidiana. O mundo do emprego desabou. O sistema financeiro tal qual era organizado implodiu. Vieram Brexit, Trump e a COVID-19. O mundo mudou: muito e de forma extraordinariamente rápida.

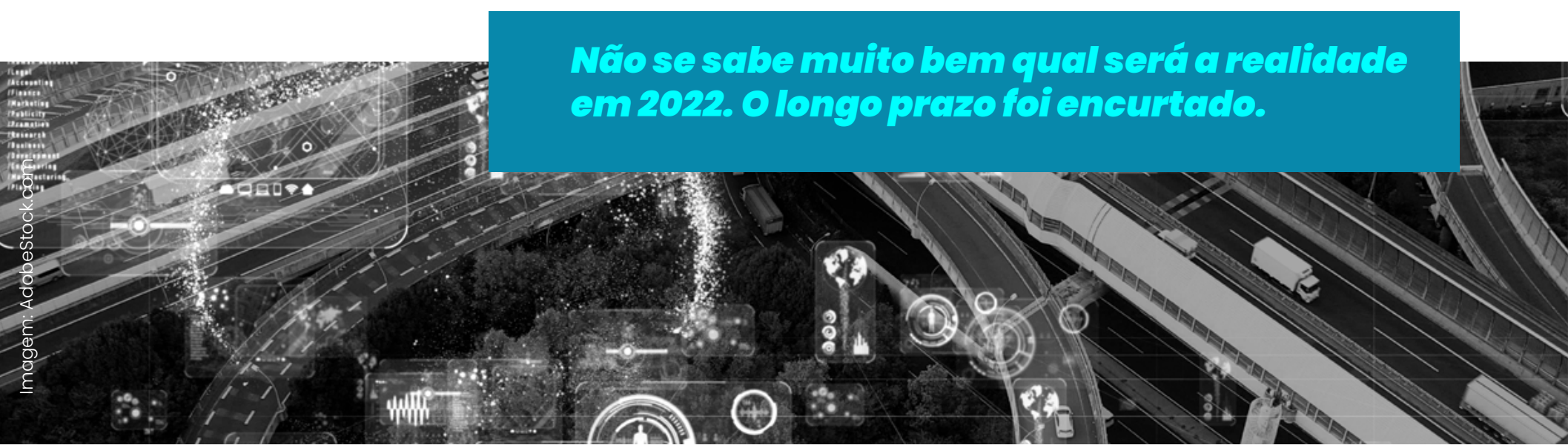

Na verdade, não se tem clareza do estado das coisas no presente, em função dos sinais contraditórios captados. Uma densa neblina baixou sobre o país. Os instrumentos provedores de leituras dos eventos - o conhecimento estruturado acumulado nas universidades, a reputação de experts no mundo privado, as instituições governamentais provedoras de dados e os filtros proporcionados pelos meios de comunicação em massa da grande mídia - encontram-se em prolongada agonia. 
Neste ambiente de vertiginosas mudanças, nunca foi tão importante discernir o que é relevante em meio a essa cacofonia generalizada. Historicamente, o crescimento econômico sempre esteve correlacionado com a expansão da indústria. O valor agregado pela indústria encontrava-se no centro das explicações relacionadas ao desenvolvimento dos países ricos, em função de seus contínuos ganhos de produtividade, mesmo quando o setor financeiro globalizou-se e os bancos de investimento tornaram-se as grandes alavancas da abundância. Petróleo, carros, químicos, fármacos, infraestrutura, siderurgia, alimentos, cosméticos, metalmecânica, agroindústria, eletrodomésticos, mineração, papel e celulose, têxtil, telecomunicações, equipamentos hospitalares ...

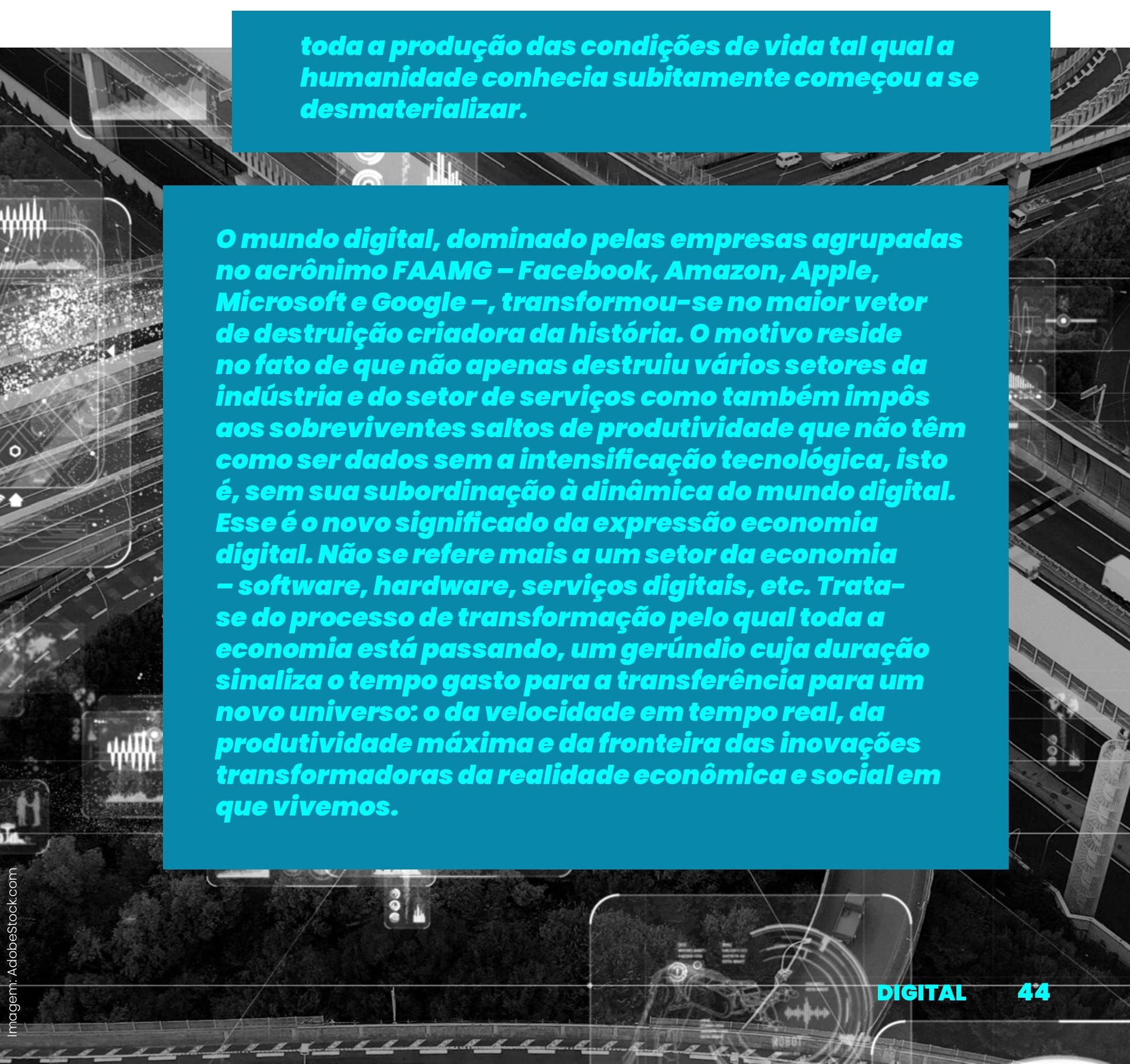


Aos problemas tradicionais - concorrência, juros, carga tributária, burocracia, etc. - , a conversão tecnológica agrega um conjunto de novas ferramentas, modus operandi e inovações as mais variadas, impulsionadas por um conjunto de abordagens e tecnologias que incluem inteligência artificial, realidade aumentada, nuvens, internet das coisas, blockchain, criptomoedas, etc. Trata-se de uma situação desafiadora, em especial porque a maioria das empresas tem no comando maiores de quarenta anos; grande parte formada em um mundo anterior ao surgimento de mecanismos de busca e celulares inteligentes, o que gera o chamado desafio geracional.

\section{Atucr proctivemente no sentido de enteciperr-se ce futuroe elbreçerr sucs oportunidedes é terrefa que depende de uma nova gerç̧ăo de empreendedores, nầo dos dirrigentes, proprietários e acionistas estibelecidos.}

Em outras palavras, o comando das decisões empresariais é ocupado por uma geração de um outro tempo histórico de padrão de produção. Apenas as lideranças capazes de pensar além de si serão capazes de se aliar à juventude na modelagem do futuro da indústria.

A aceleração da transformação digital das empresas e governos pelo mundo afora diminui o espaço de manobra do país para se colocar como uma moderna economia digital, capaz de atrair novos investimentos e ganhar competitividade. As barreiras que impedem o Brasil de avançar nessa direção são várias, incluindo uma precária infraestrutura digital no governo, um arcabouço regulatório limitado, uma exclusão acentuada de parte significativa da população e, principalmente, uma força de trabalho despreparada para responder aos desafios do mundo digital. A revolução digital traz embutida uma urgência que insistimos em relevar, como se ignorá-la nos absolvesse das responsabilidades e consequências envolvidas.

\section{Algumes tremsformeçōes importehtes ocorrerem nas duas últimas décadas no mereado de trabalho, alterchndo o perfill de forç de trabellho necessćtric para a transformaģão digitul da economi๘.}


A primeira foi o avanço da automação de processos com a substituição de trabalhos rotineiros por sistemas digitais e robôs. A segunda foi a inversão da pirâmide do conhecimento no campo da criação, inovação e da instrumentalização, com os pertencentes da geração mais jovem sendo capazes de dominar ferramentas digitais inacessiveis para os mais antigos. A terceira foi a explosão criativa de jovens empreendedores digitais, capazes de pensar novos negócios, disruptivos e destruidores dos existentes, sem necessariamente terem gasto muito tempo trabalhando em organizações convencionais. A quarta foi o surgimento de organizações nas quais várias gerações convivem sem nenhum tipo de correspondência com os postos hierárquicos, isto é, sem que necessariamente os mais velhos estejam no topo da pirâmide e os mais jovens na base. E a quinta foi o aparecimento e crescimento da chamada "gig economy", que é um mercado livre de serviços operados por plataformas digitais, que contratam trabalhadores independentes para tarefas de curto prazo. Só no Brasil, milhões de pessoas hoje trabalham para Uber, Rappi, ifood, Loggi, Airbnb e outras plataformas da "gig-economy".

Mundo afora, percebe-se que a transformação digital - principalmente em relação ao mundo do trabalho - polariza e divide a sociedade. Para alguns, a automação trará inovação, competitividade e perspectiva de maior liberdade pessoal. Para outros, a automação é símbolo de incerteza, menos empregos, menores salários e mais concentração de renda. Nosso futuro digital já deveria estar sendo preparado, tomando forma no cenário de uma economia mais moderna e competitiva. Não é o que está acontecendo.

A economia digital abrangerá em pouco tempo toda a economia formal e boa parte da economia informal. Apenas uma parcela da vida econômica permanecerá à margem do fluxo digital dos processos econômicos, setores próximos de situações da pobreza absoluta e da marginalidade. Toda a indústria migrará para o universo da economia digital. É uma questão de sobrevivência e de competitividade.

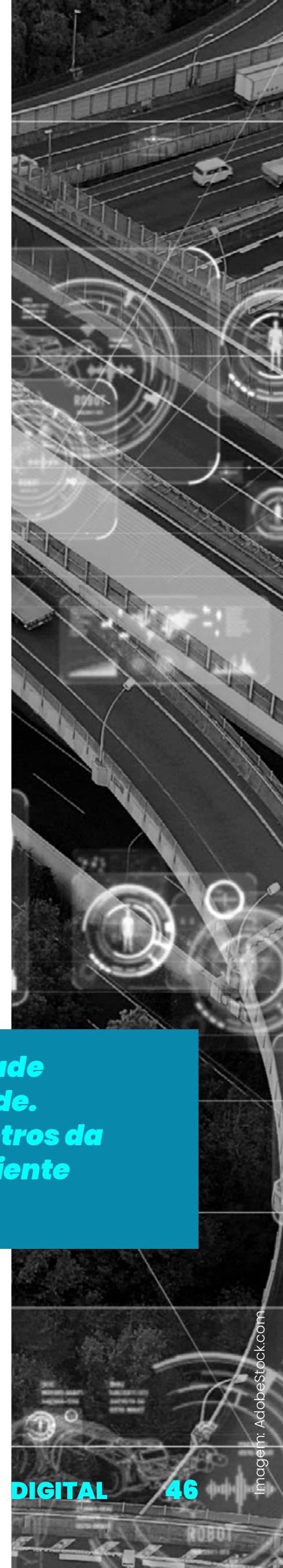




\section{Alheio, desprovido de projeto nacional e desorientado sobre que curso de açẫo adotar, o país se vê às voltas com a exccerbação das defesas de interesses particulares, incaparz de produzir consensos minimos balizadores de uma polfitica externa consistente e de polfticas industrial, cientifica, tecnolögicas e de inovaçấo adequadas às exigêneias do momento presente e do futuro que está passcindo.}

Políticos, sindicatos e líderes empresariais devem buscar um diálogo público para que a mudança tecnológica leve à criação de empregos de qualidade no país. Esse diálogo deveria buscar respostas a muitas questões. Como nossas políticas de emprego, educação, industrial, de ciência e tecnologia estão abordando os desafios da robotização? Como nossas universidades estão se movendo para atender à brutal escassez de mão de obra nestes setores tecnológicos nas próximas décadas? Como o nosso setor privado está, ele mesmo, proporcionando o desenvolvimento de capacidades digitais in-house para ser mais competitivo e dotado de maior produtividade? Como os sindicatos estão planejando a requalificacão de trabalhadores?

- futuro da indústrịa é digițal. Homem, máquina, algoritmos e inteligêneia artificial se combinarẫo de múltiplas formas nas próximas déeadas. Não há como alegar desconhecimento. Desinterditar o futuro é enfrentar as escolhas que essas tendências nos

\section{apresentam.}




\section{NOTASEREFERÊNCIAS}

1 Ver a reconfiguração do mapa das profissões do futuro, contidas no "The Future of Jobs Report 2020", World Economic Forum, October 2020. http://www3.weforum.org/docs/WEF_Future_of_Jobs_2020.pdf 